\title{
Impact of $\mathbf{T}$ status and $\mathbf{N}$ status on perioperative outcomes after thoracoscopic lobectomy for lung cancer
}

\author{
Nestor R. Villamizar, MD, Marcus Darrabie, MD, Jennifer Hanna, MD, Mark W. Onaitis, MD, \\ Betty C. Tong, MD, Thomas A. D’Amico, MD, and Mark F. Berry, MD
}

Objective: We sought to evaluate the effect of tumor size, location, and clinical nodal status on outcomes after thoracoscopic lobectomy for lung cancer.

\begin{abstract}
Methods: All patients who underwent attempted thoracoscopic lobectomy for lung cancer between June 1999 and October 2010 at a single institution were reviewed. A model for morbidity including published risk factors as well as tumor size, location, and clinical $\mathrm{N}$ status was developed by multivariable logistic regression.
\end{abstract}

Results: During the study period, 916 thoracoscopic lobectomies met study criteria: 329 for peripheral, clinical N0 tumors $\leq 3 \mathrm{~cm}$ and 504 for tumors that were central, clinical node positive, or $>3 \mathrm{~cm}$. Tumor location could not be documented for 83 patients. Conversions to thoracotomy occurred in 36 patients $(4 \%)$; patients with clinically node-positive disease had higher conversion rates ( 11 conversions in 153 clinical N1 to N3 patients [7.2\%] vs 25 in 763 clinical N0 patients [3.3\%, $P=.03]$. Overall operative mortality was $1.6 \%$ (14 patients) and morbidity was $32 \%$ (296 patients). Although patients with larger tumors $(P=.006)$ and central tumors $(P=.01)$ had increased complications by univariate analysis, tumor size $>3 \mathrm{~cm}(P=.17)$ and central location $(P=.5)$ did not predict significantly overall morbidity in multivariate analysis. Clinical node status did not predict increased complications by univariate or multivariate analysis. Significant predictors of morbidity in multivariable analysis were increasing age, decreasing forced expiratory volume in 1 second, prior chemotherapy, and congestive heart failure.

Conclusions: Thoracoscopic lobectomy for lung cancers that are central, clinically node positive, or $>3 \mathrm{~cm}$ does not confer increased morbidity compared with peripheral, clinical N0 cancers that are $<3 \mathrm{~cm}$. (J Thorac Cardiovasc Surg 2013;145:514-21)

Earn CME credits at

http://cme.ctsnetjournals.org

A thoracoscopic approach to lobectomy has less morbidity compared with thoracotomy and has been advocated to be the gold standard resection approach for early-stage nonsmall cell lung cancer (NSCLC). ${ }^{1-6}$ The feasibility of performing a thoracoscopic lobectomy for lung nodules $<3 \mathrm{~cm}$ suspected to be NSCLC was demonstrated by a prospective, multi-institution trial. ${ }^{7}$ Although thoracoscopic techniques for more advanced tumors and resections have been reported, there is a lack of literature on the impact of attempting a thoracoscopic lobectomy for larger, central,

From the Division of Thoracic Surgery, Department of Surgery, Duke University Medical Center, Durham, NC.

This work was in part supported by the National Institutes of Health-funded Cardiothoracic Surgery Trials Network (to M.F.B.).

Disclosures: Authors have nothing to disclose with regard to commercial support.

Read at the 38th Annual Meeting of The Western Thoracic Surgical Association, Maui, Hawaii, June 27-30, 2012.

Received for publication June 18, 2012; revisions received Sept 23, 2012; accepted for publication Oct 22, 2012; available ahead of print Nov 22, 2012.

Address for reprints: Mark F. Berry, MD, Box 3652, Duke University Medical Center, Durham, NC 27710. (E-mail: berry037@mc.duke.edu).

$0022-5223 / \$ 36.00$

Copyright (C) 2013 by The American Association for Thoracic Surgery

http://dx.doi.org/10.1016/j.jtcvs.2012.10.039 and higher stage tumors. ${ }^{8-12}$ This study was performed to evaluate the effect of tumor size, location, and clinical nodal status on outcomes after thoracoscopic lobectomy for NSCLC. The purpose of the study was to test the hypothesis that performing a thoracoscopic lobectomy for tumors that are $>3 \mathrm{~cm}$, have a central location, or have clinically positive lymph nodes does not have increased perioperative morbidity compared with thoracoscopic lobectomy for peripheral tumors that are $<3 \mathrm{~cm}$ and have clinically negative nodes.

\section{METHODS}

After local institutional review board approval was granted, the Duke University Medical Center Data Center was queried for Current Procedural Terminology codes linked with pulmonary resection by a thoracoscopic approach between June 1999 and October 2010. Careful attention was paid to individual operative notes and surgical pathology reports to identify all patients who underwent anatomic lobectomy via thoracoscopy for primary lung cancer. Patients who had attempted lobectomy via thoracoscopy but had conversions to thoracotomy for any reason were included in the thoracoscopic group for the analysis. Patients who had resection of $>1$ lobe or who underwent concomitant chest wall resection were excluded from the study.

Retrospective review of an institutional, prospective database maintained on all thoracic surgery patients was performed. Data collected included demographics, preoperative functional status, the use of induction therapy, smoking history, significant comorbidities, the histology and stage of disease, intraoperative details, and postoperative course. Chart review was used as necessary to complete data collection. Any postoperative event prolonging or otherwise altering the postoperative course was recorded along with all operative deaths, which were defined as deaths that occurred 


\section{Abbreviations and Acronyms \\ FEV1 = forced expiratory volume in 1 second \\ NSCLC $=$ non-small cell lung cancer \\ PET = positron emission tomography \\ VATS $=$ video-assisted thorascopic surgery}

within 30 days after operation or those that occurred later but during the same hospitalization. Deaths were captured both by chart review and use of the Social Security Death Index Database. The definitions of postoperative events were based on version 2.08 of the Society of Thoracic Surgeons General Thoracic Surgery Database. ${ }^{13}$ Morbidity was defined as the occurrence of at least 1 of these postoperative events. This composite end point definition was chosen because all events can cause patient discomfort, require additional testing and treatment, lead to longer hospital stays, and increase overall costs, and thus are all clinically significant.

The recorded tumor size was that of the largest nodule in cases in which $>1$ nodule was present. Tumor location definition was based on location of tumor relative to branching lobar bronchi and blood vessels. A tumor was classified as central if removal would require division of lobar structures that would render any remaining lobar lung tissue nonfunctional. Tumors that could be removed via wedge resection while leaving remaining functional lobar lung tissue were classified as peripheral. Therefore, tumors for which a wedge resection could be performed to establish diagnosis prior to completion lobectomy were classified as peripheral. Tumors for which a diagnosis had not been established prior to resection but were considered not to be amenable to wedge at the time of resection by the operating surgeon were classified as central. Preresection imaging for all other patients was reviewed by an attending thoracic surgeon (M.F.B.), and was classified as central/peripheral based on the previous criteria.

In cases when clinical $\mathrm{N}$ stage was not recorded explicitly prior to resection, pretreatment imaging was reviewed to establish the clinical $\mathrm{N}$ stage. Nodes were considered clinically positive if an official positron emission tomography (PET) report described the presence of nodal activity suspicious for metastatic disease. The actual values for the standardized update ratio were not provided routinely in PET scans at our institution. For patients who had computed tomographic scans but not PET scans, patients were considered clinically $\mathrm{N}$ positive if the official radiology report described abnormally enlarged lymph nodes $>1 \mathrm{~cm}$ in the short axis. When patients had both computed tomographic and PET scans, the PET result was used to determine clinical stage.

Thoracoscopic lobectomy was performed without any rib spreading with the thoracoscope placed in the 8th intercostal space in the midaxillary line and a 4 to $5-\mathrm{cm}$ anterior utility incision in the 5th intercostal space. ${ }^{14}$ An epidural catheter for postoperative pain relief was offered routinely to all patients regardless of planned operative approach. Chest tubes were placed routinely on water seal immediately postoperatively and were removed when no air leak was present and drainage over 24 hours was $<200 \mathrm{~mL}$.

Univariate analyses were performed relating operative morbidity to the following patient characteristics: age, tumor size $(\leq 3 \mathrm{~cm}$ vs $>3 \mathrm{~cm})$, tumor location (central vs peripheral), clinical N stage (N0 vs N1-N3), the presence of diabetes mellitus, the presence of renal insufficiency, history of prior chemotherapy, history of prior radiation, a history of smoking, history of congestive heart failure, history of coronary artery disease, previous thoracic surgery, and preoperative pulmonary function tests (forced expiratory volume in 1 second [FEV1] and diffusion capacity of the lung to carbon monoxide). Tumor size was analyzed as classified as noted earlier and not according to $\mathrm{T}$ stage to account for tumors in which $\mathrm{T}$ stage was upstaged as a result of the presence of additional nodules in the lobe or pleural involvement. The variables that were significant at $P<.20$ were entered into a multivariable logistic regression with morbidity as the dependent variable, and significance set at the .05 level.
Propensity score analysis that created subclasses of patients with central and peripheral tumors with similar covariate distributions was used as an alternative method of assessing the impact of tumor location on overall morbidity. Multivariable analysis was performed with tumor location as the outcome and age, percent predicted FEV1, percent predicted diffusion capacity of the lung to carbon monoxide, tumor size $(\leq 3 \mathrm{~cm}$ vs $>3 \mathrm{~cm}$ ), clinical N stage (N0 vs N1-N3), a history of smoking, history of coronary artery disease, previous thoracic surgery, and history of prior chemotherapy as potential predictors. Propensity scores were calculated using a logistic regression model that was created using stepwise variable selection with a $P$ value of .2 for entry into the model and a $P$ value of .05 to stay in the model. Only patients with propensity scores between 0.40 and 0.60 were then included in subsequent analysis in which baseline characteristics and outcomes were compared based on tumor location.

Unpaired Student $t$ tests were used to compare continuous data, Fisher exact tests for dichotomous data, and $\chi^{2}$ for categorical variables. A 2 -tailed $P$ value of $<.05$ was considered significant. Data are presented as mean \pm standard error of the mean unless otherwise noted. The SAS 9.0 statistical package (SAS Institute, Cary, NC) was used for statistical analyses.

\section{RESULTS}

Of 1195 thoracoscopic lobectomies performed during the study period, 916 met the study criteria. Overall, $620(68 \%)$ lobectomies were for tumors $\leq 3 \mathrm{~cm}$ in size (median, $2 \mathrm{~cm}$ ) and $296(32 \%)$ lobectomies were for tumors $>3 \mathrm{~cm}$ in size (median, $4.3 \mathrm{~cm})$. Most patients $(\mathrm{n}=763,83 \%)$ were clinical stage N0, whereas $153(17 \%)$ were clinical stage N1 to N3. Of the patients with tumors $>3 \mathrm{~cm}, 213$ patients had tumors between $3.1 \mathrm{~cm}$ and $5 \mathrm{~cm}, 60$ between $5.1 \mathrm{~cm}$ and $7 \mathrm{~cm}$, and $23>7 \mathrm{~cm}$. Tumor location could not be documented for 83 patients. Of 833 patients with documented tumor location, 487 tumors $(58 \%)$ were peripheral and $346(42 \%)$ were central.

The number of thoracoscopic lobectomies per year, both overall and stratified by peripheral T1AN0 versus other, is depicted in Figure 1. Overall, 329 patients (39\%) had peripheral, clinical N0 tumors $\leq 3 \mathrm{~cm}$ and 504 patients $(61 \%)$ had tumors that were $>3 \mathrm{~cm}$, central, or clinical node positive. The percentage of procedures performed for larger tumors, central tumors, and clinically positive nodal disease all trended upward throughout the course of the study period (Figure 2). Over the same time frame, 541 lobectomies via thoracotomy ( 89 sleeve resections) were performed. The pathologic stage distribution of the thoracotomy lobectomies was 73 patients stage IA $(13 \%), 109$ patients stage IB $(20 \%), 119$ patients stage IIA (22\%), 76 patients stage IIB $(14 \%), 140$ patients stage IIIA $(26 \%), 11$ patients stage IIIB $(2 \%)$, and 11 patients stage IV $(2 \%)$.

Demographic, baseline characteristics, and comorbid conditions are shown in Table 1. Compared with patients with tumors that were peripheral, $<3 \mathrm{~cm}$, and had clinically negative nodes, patients with central tumors, tumors $>3 \mathrm{~cm}$, or clinically positive nodes had worse pulmonary function and were more likely to have had coronary artery disease, previous thoracic surgery, and induction chemotherapy. The ages of these 2 groups were not significantly different, 


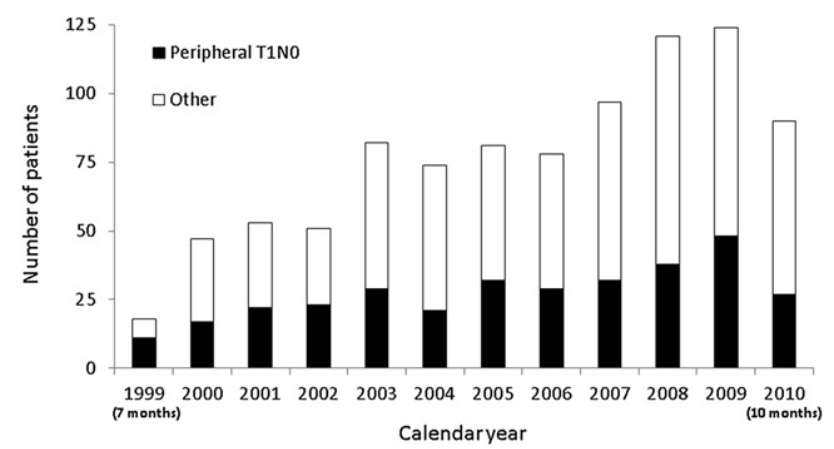

FIGURE 1. Distribution of thoracoscopic lobectomy for smaller and larger tumors per study year. (Note: The year 1999 only included 7 months for analysis; 2010 only included 10 months for analysis.)

and the incidences of smoking history, diabetes mellitus, prior radiation, congestive heart failure, and renal insufficiency were also not significantly different.

Outcomes are summarized in Table 1. Overall operative mortality was $1.6 \%$ (14 patients) and morbidity was $32 \%$ (296 patients). The median chest tube duration for all patients was 3 days; the median hospitalization was 4 days. The most common postoperative events were atrial arrhythmia $(\mathrm{n}=128,14 \%)$, air leak $>5$ days $(\mathrm{n}=107,12 \%)$, postoperative bronchoscopy $(\mathrm{n}=54,6 \%)$, and postoperative transfusion $(n=47,5 \%)$. Table 1 also shows the final pathologic stage for the patients in the study. As expected, patients with smaller, peripheral, clinically node-negative tumors were much more likely to be pathologic stage I than patients with larger, central, or clinically nodepositive tumors. Of the 763 patients who had clinically node-negative tumors, 98 patients $(13 \%)$ were upstaged to pathologic $\mathrm{N} 1(10 \%, \mathrm{n}=77)$ or pathologic $\mathrm{N} 2(3 \%, \mathrm{n}=21)$.

In univariate analysis, patients with central tumors, tumors $>3 \mathrm{~cm}$, or clinically positive nodes had increased overall morbidity, as well as increased rates of prolonged air leaks, postoperative bronchoscopy, postoperative transfusion, and reintubation compared with the patients with tumors that were peripheral, $<3 \mathrm{~cm}$, and had clinically negative nodes. However, multivariate analysis did not demonstrate tumor size, location, or nodal status to be significant risk factors for overall morbidity (Table 2). Although patients with larger tumors $(P=.006)$ and central tumors $(P=.01)$ had increased complications by univariate analysis, tumor size $>3 \mathrm{~cm}(P=.17)$ and central location $(P=.5)$ did not predict overall morbidity significantly in multivariate analysis. Clinical node status did not predict increased complications by univariate or multivariate analysis. The significant predictors of morbidity by multivariable analysis were age, FEV1 prior chemotherapy, and congestive heart failure.

Propensity score analysis identified 135 patients with central tumors and 122 patients with peripheral tumors with similar baseline characteristics (Table 3 ). There were no

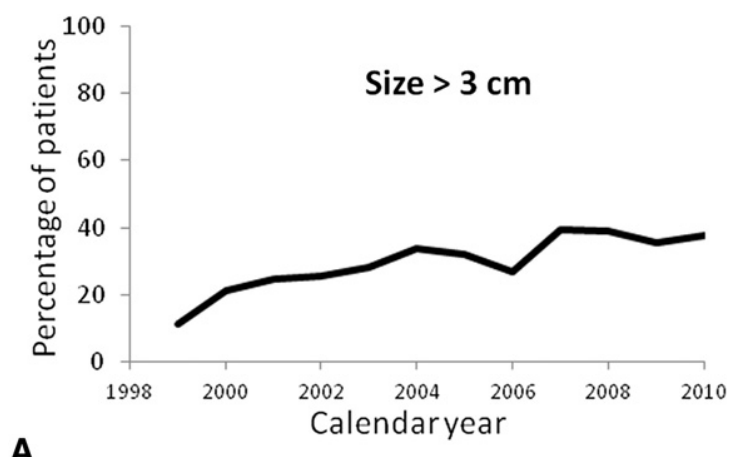

A

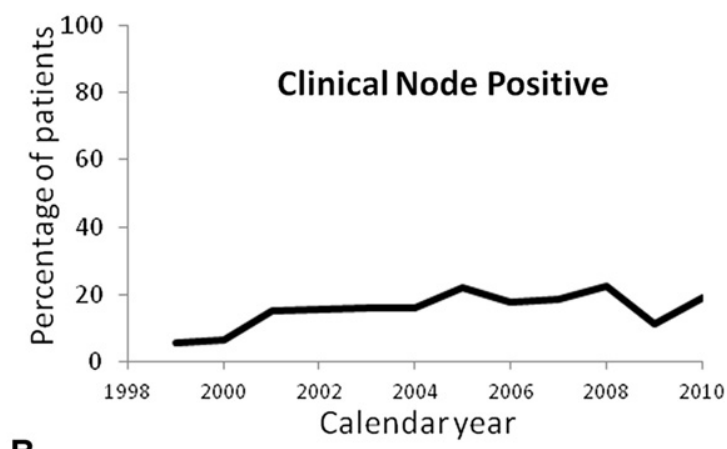

B

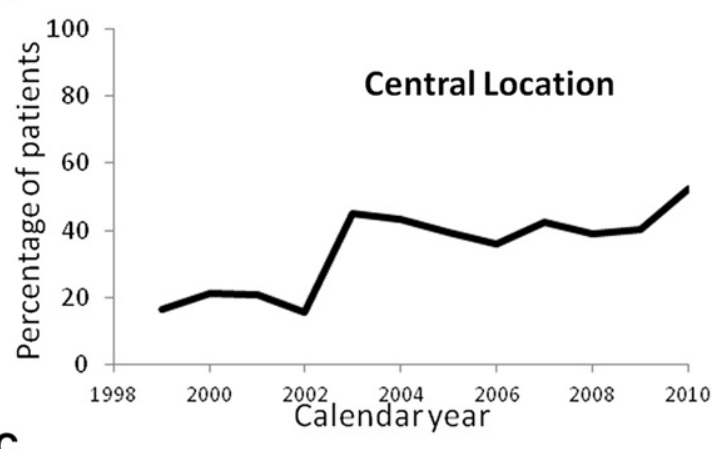

C

FIGURE 2. A-C, Percentage of thoracoscopic lobectomy performed in each year of the study for tumors $>3 \mathrm{~cm}$ (A), tumors with clinically positive nodal disease (B), and tumors in a central location (C).

statistically significant differences in perioperative mortality, overall morbidity, or hospital stay between the patients with central tumors and the patients with peripheral tumors. These results are consistent with the previously described multivariate analysis results that show central location does not predict increased overall morbidity independently.

Other stratifications of tumor size were also evaluated to assess the impact of tumor size on outcomes. The difference between morbidity of patients with tumors $>5 \mathrm{~cm}(40 \%, 33$ of 83 patients) and patients with tumors $<5 \mathrm{~cm}(32 \%, 263$ of 833) was not statistically significant $(P=.1)$. Morbidity stratified by more discrete size subgroups were as follows: $29 \%$ (182 of 620 patients) for tumors $<3 \mathrm{~cm}, 38 \%$ ( 81 of 213 patients) for tumors between $3 \mathrm{~cm}$ and $5 \mathrm{~cm}, 43 \%$ (26 of 60 patients) for tumors between $5 \mathrm{~cm}$ and $7 \mathrm{~cm}$, and $30 \%$ ( 7 of 23 patients) for tumors $>7 \mathrm{~cm}$. 
TABLE 1. Demographics and perioperative outcomes for all patients and stratified by tumor size, location, and clinical $\mathrm{N}$ status

\begin{tabular}{|c|c|c|c|c|}
\hline & $\begin{array}{l}\text { All patients } \\
(\mathbf{n}=916)\end{array}$ & $\begin{array}{c}\text { Peripheral, } \leq 3 \mathrm{~cm}, \text { and } \\
\text { clinical No }(\mathrm{n}=329)\end{array}$ & $\begin{array}{c}\text { Central, }>3 \mathrm{~cm}, \text { or clinical } \\
\text { N1-N3 }(n=504)\end{array}$ & $P$ value* \\
\hline \multicolumn{5}{|l|}{ Baseline characteristics } \\
\hline Median age, y (range) & $67(21-93)$ & $67(38-88)$ & $68(21-93)$ & .2 \\
\hline$\%$ Predicted forced expiratory volume in 1 second, $\%$ & $74 \pm 20$ & $78 \pm 21$ & $72 \pm 20$ & $<.0001$ \\
\hline$\%$ Predicted diffusion capacity to carbon monoxide & $77 \pm 21$ & $82 \pm 21$ & $75 \pm 21$ & $<.0001$ \\
\hline Smoking history, $\mathrm{n}(\%)$ & $792(86)$ & $274(83)$ & $444(88)$ & .051 \\
\hline Coronary artery disease, $\mathrm{n}(\%)$ & $196(21)$ & $61(18)$ & $125(25)$ & .04 \\
\hline Diabetes, n (\%) & $150(16)$ & $60(18)$ & $80(16)$ & .4 \\
\hline Previous thoracic surgery, $\mathrm{n}(\%)$ & $144(16)$ & $39(12)$ & $92(18)$ & .01 \\
\hline Prior chemotherapy, n (\%) & $60(6)$ & $9(3)$ & $48(10)$ & .0001 \\
\hline Prior radiation, $\mathrm{n}(\%)$ & $48(5)$ & $14(4)$ & $31(6)$ & .3 \\
\hline Congestive heart failure, $\mathrm{n}(\%)$ & $43(5)$ & $18(5)$ & $22(4)$ & .4 \\
\hline Renal insufficiency, n (\%) & $41(4)$ & $13(4)$ & $26(5)$ & .5 \\
\hline \multicolumn{5}{|l|}{ Outcomes } \\
\hline Perioperative mortality, n (\%) & $14(1.6)$ & $4(1.2)$ & $8(1.6)$ & .8 \\
\hline Conversion, $\mathrm{n}(\%)$ & $36(4)$ & $11(3)$ & $23(5)$ & .5 \\
\hline Hospital stay, Days & $4.9 \pm 4.3$ & $4.4 \pm 3.7$ & $5.3 \pm 4.8$ & .005 \\
\hline Hospital stay $>14 \mathrm{~d}, \mathrm{n}(\%)$ & $25(3)$ & $6(2)$ & $19(4)$ & .15 \\
\hline Overall morbidity, n (\%) & $296(32)$ & $85(26)$ & $188(37)$ & .0007 \\
\hline Pathologic stage, $\mathrm{n}(\%)$ & & & & $<.0001$ \\
\hline Stage I & $634(69)$ & $280(85)$ & $296(59)$ & \\
\hline Stage II-IV & $282(31)$ & $49(15)$ & $208(41)$ & \\
\hline Atrial fibrillation, $\mathrm{n}(\%)$ & $128(14)$ & $41(12)$ & $76(15)$ & .3 \\
\hline Prolonged air leak > $5 \mathrm{~d}, \mathrm{n}(\%)$ & $107(12)$ & $28(9)$ & $70(14)$ & .02 \\
\hline Need for postoperative bronchoscopy, n (\%) & $54(6)$ & $9(3)$ & $44(9)$ & .0004 \\
\hline Postoperative transfusion, $\mathrm{n}(\%)$ & $47(5)$ & $12(4)$ & $34(7)$ & .06 \\
\hline Pneumonia, n $(\%)$ & $30(3)$ & $8(2)$ & $21(4.2)$ & .2 \\
\hline Need for new chest tube, $\mathrm{n}(\%)$ & $22(2)$ & $5(2)$ & $16(3)$ & .2 \\
\hline Confusion/delirium, n (\%) & $16(2)$ & $4(1)$ & $11(2)$ & .4 \\
\hline Reintubation, n (\%) & $15(2)$ & $1(0.3)$ & $14(3)$ & .007 \\
\hline Renal failure, n (\%) & $13(1)$ & $5(2)$ & $8(2)$ & 1 \\
\hline Myocardial infarction, n (\%) & $4(0.4)$ & 0 & $3(0.6)$ & .3 \\
\hline Tracheostomy, n (\%) & $4(0.4)$ & $1(0.3)$ & $3(0.6)$ & 1 \\
\hline Reoperation for bleeding, $\mathrm{n}(\%)$ & $3(0.3)$ & 0 & $3(0.6)$ & .3 \\
\hline Empyema & $3(0.3)$ & $1(0.3)$ & $2(0.4)$ & 1 \\
\hline
\end{tabular}

Data is presented as count and percentage or mean \pm standard deviation, as appropriate. ${ }^{*}$ Comparison between peripheral, $\leq 3 \mathrm{~cm}$, and clinical $\mathrm{N} 0 \mathrm{vs}$ central, $>3 \mathrm{~cm}$, or clinical $\mathrm{N} 1$ to $\mathrm{N} 3$.

Conversions to thoracotomy occurred in 36 patients (4\%). Conversion was achieved by enlarging the anterior utility incision in 19 patients and performing a posterolateral thoracotomy in 15 patients; the conversion method wasn't specified in 2 patients. Conversion indication was bleeding in 21 patients (pulmonary artery branch, $n=16$; unspecified location, $\mathrm{n}=2$; pulmonary vein, $\mathrm{n}=1$; bronchial vessel, $\mathrm{n}=1$; and lung parenchyma, $\mathrm{n}=1$ ) and difficult dissection/hilar adenopathy in 9 patients. In addition, conversions were made in 1 patient for each of the following reasons: inability to locate nodule, pulmonary artery invasion, need to perform pulmonary arterioplasty after lobectomy resulted in stenosis, inability to maneuver the lung, failure to progress, and failure to obtain adequate lung isolation. None of the conversions resulted in intraoperative death, and the difference in perioperative mortality between patients that required conversion and patients without conversion was not statistically significant $(5.6 \%$ [2 of 36 patients] vs $1.4 \%$ [12 of 880 patients], $P=.1$ ). Patients who required conversion did have significantly higher overall morbidity compared with patients without conversion $(61 \%$ [22 of 36 patients] vs $31 \%$ [274 of 880 patients], $P=.0004)$. The individual complication that was significantly higher in the converted patients was postoperative transfusion $(25 \%$ [9 of 36 patients] vs $4 \%$ [ 38 of 880 patients], $P<.0001)$. The conversion rate was not higher for tumors $>3 \mathrm{~cm}$ (12 conversions in 296 patients [ $4 \%$ ] with tumors $>3 \mathrm{~cm}$ vs 24 conversions in 620 patients [3.9\%] with tumors $<3 \mathrm{~cm}, P=.7$ ) or for central tumors (17 conversions in 346 patients [4.9\%] with central tumors vs 17 conversions in 487 patients [3.5\%] with peripheral tumors, $P=.3$ ). The conversion rate was increased for patients with clinically node-positive disease ( 11 conversions in 153 clinical N1-N3 patients [7.2\%] vs 25 conversions in 763 clinical N0 patients [3.3\%], $P=.03$ ). 
TABLE 2. Multivariate risk model for complications

\begin{tabular}{|c|c|c|c|c|}
\hline \multirow[b]{2}{*}{ Variable } & \multirow[b]{2}{*}{$\begin{array}{c}\text { Univariate } \\
P \text { value }\end{array}$} & \multicolumn{3}{|c|}{ Multivariate analysis } \\
\hline & & $\begin{array}{l}\text { Odds } \\
\text { ratio }\end{array}$ & $\begin{array}{c}95 \% \\
\text { Confidence } \\
\text { interval }\end{array}$ & $\begin{array}{c}P \\
\text { value }\end{array}$ \\
\hline Age per 1-year increase & $<.0001$ & 1.06 & $1.04-1.08$ & $<.0001$ \\
\hline $\begin{array}{l}\% \text { Predicted forced expiratory } \\
\text { volume in } 1 \text { second per } 1 \% \\
\text { increase }\end{array}$ & $<.0001$ & 0.98 & $0.97-0.99$ & $<.0001$ \\
\hline Prior chemotherapy & .02 & 2.40 & $1.14-5.08$ & .02 \\
\hline Congestive heart failure & .003 & 2.16 & $1.03-4.54$ & .04 \\
\hline $\begin{array}{l}\% \text { Predicted diffusion capacity } \\
\text { to carbon monoxide per } 1 \% \\
\text { decrease }\end{array}$ & $<.0001$ & & & .1 \\
\hline Tumor size $>3 \mathrm{~cm}$ vs $\leq 3 \mathrm{~cm}$ & .006 & & & .17 \\
\hline $\begin{array}{l}\text { Tumor location (central vs } \\
\text { peripheral) }\end{array}$ & .01 & & & .5 \\
\hline Previous thoracic surgery & .009 & & & .5 \\
\hline Smoking history & .04 & & & 6 \\
\hline Coronary artery disease & .004 & & & .8 \\
\hline Prior radiation therapy & .16 & & & 1 \\
\hline Diabetes & .4 & & & \\
\hline Clinical N stage (N1-N3 vs N0) & .5 & & & \\
\hline Renal insufficiency & 6 & & & \\
\hline
\end{tabular}

\section{DISCUSSION}

Thoracoscopic lobectomy was first reported in the 1990s and, since then, several studies have shown advantages to this technique over thoracotomy. These advantages include

TABLE 3. Baseline characteristics and outcomes for centrally and peripheral located tumors after propensity scoring used to create subclasses of patients with similar baseline characteristic distributions

\begin{tabular}{|c|c|c|c|}
\hline & $\begin{array}{c}\text { Central } \\
\text { tumors } \\
(\mathbf{n}=\mathbf{1 3 5}) \\
\end{array}$ & $\begin{array}{c}\text { Peripheral } \\
\text { tumors } \\
(\mathrm{n}=\mathbf{1 2 2})\end{array}$ & $\begin{array}{c}P \\
\text { value } \\
\end{array}$ \\
\hline \multicolumn{4}{|l|}{ Baseline characteristics } \\
\hline Age, years & $67.5 \pm 8.6$ & $67.5 \pm 9.3$ & 1 \\
\hline $\begin{array}{l}\% \text { Predicted forced expiratory } \\
\text { volume in } 1 \text { second }\end{array}$ & $68 \pm 21$ & $70 \pm 22$ & .5 \\
\hline $\begin{array}{l}\% \text { Predicted diffusion capacity to } \\
\text { carbon monoxide }\end{array}$ & $72 \pm 22$ & $72 \pm 18$ & .9 \\
\hline History of smoking, $(\%)$ & $124(92)$ & $107(88)$ & .3 \\
\hline Coronary artery disease, $(\%)$ & $40(30)$ & $23(19)$ & .06 \\
\hline Previous thoracic surgery, $(\%)$ & $17(13)$ & $19(16)$ & 6 \\
\hline Prior chemotherapy, $(\%)$ & $11(8)$ & $6(5)$ & .4 \\
\hline Tumor size, $(\%)$ & & & .2 \\
\hline$\leq 3 \mathrm{~cm}$ & $40(30)$ & $46(38)$ & \\
\hline$>3 \mathrm{~cm}$ & $95(70)$ & $76(62)$ & \\
\hline Clinical nodal status, $(\%)$ & & & .3 \\
\hline Clinical NO & $102(76)$ & $99(81)$ & \\
\hline Clinical N1-N3 & $33(24)$ & $23(19)$ & \\
\hline \multicolumn{4}{|l|}{ Outcome variables } \\
\hline Perioperative mortality, $(\%)$ & $3(2.2)$ & $2(1.6)$ & 1 \\
\hline Overall morbidity, $(\%)$ & $56(41)$ & $44(36)$ & .4 \\
\hline Hospital stay, days & $5.3 \pm 3.6$ & $5.8 \pm 6.7$ & .4 \\
\hline
\end{tabular}

Data is presented as count and percentage or mean \pm standard deviation, as appropriate. less pain, better pulmonary function, shorter hospitalization, decreased overall costs, and fewer overall complications. ${ }^{1-5,14-21}$ Despite these demonstrated advantages, a thoracoscopic approach was used in less than $45 \%$ of lobectomies as recently as $2010 .{ }^{22}$

The relatively limited application of thoracoscopic lobectomy is likely multifactorial, including surgeon training, experience, preferences, and biases. Concerns regarding safety, completeness of oncologic resection, and technical difficulties may also have prevented more widespread use of the thoracoscopic technique. Indeed, increased $\mathrm{T}$ and $\mathrm{N}$ stages, hilar adenopathy, previous thoracic radiation, and induction therapy were all considered contraindications to thoracoscopic lobectomy even in the mid $2000 \mathrm{~s}^{23}$ The prospective multicenter trial that was performed to evaluate the feasibility of this technique limited inclusion to patients with small, peripheral, clinical stage $1 \mathrm{~A}$ tumors. ${ }^{7}$ However, thoracoscopic lobectomy has been associated with improved compliance to adjuvant chemotherapy compared with thoracotomy. ${ }^{24,25}$ Considering the importance of multimodality therapy to survival of advanced-stage lung cancer, investigation into the use of thoracoscopic lobectomy in these cases is warranted.

The purpose of the current study was to analyze the impact of tumor size, location, and clinical $\mathrm{N}$ stage on outcomes after thoracoscopic lobectomy for lung cancer. In this study, overall operative mortality and morbidity was comparable with reported outcomes for thoracoscopic lobectomy in the Society of Thoracic Surgeons database. ${ }^{2}$ A high proportion of patients $(55 \%)$ had tumors that were either $>3 \mathrm{~cm}$ in size, central, or clinical node positive. None of these characteristics was associated with increased postoperative complications by multivariate analysis. The factors that were significant predictors of morbidity in multivariable analysis were increasing age, decreasing FEV1, prior chemotherapy, and congestive heart failure. Our results demonstrate that thoracoscopic lobectomy is safe and feasible for lung cancers that are central, clinically node positive, or $>3 \mathrm{~cm}$ in size.

Other recent studies have also shown the safety of thoracoscopic lobectomy in locally advanced lung cancer, including a retrospective review of 114 patients who underwent lobectomy for advanced clinical stage NSCLC between January 1, 2002, and July 31, 2007. ${ }^{8}$ Advanced clinical stage NSCLC was defined as tumors $\geq 4 \mathrm{~cm}$, T3 or T4 (based on the American Joint Committee on Cancer, 6th edition), and/or tumors that received neoadjuvant chemotherapy. Thoracoscopic lobectomy was attempted in 95 patients and completed in 73 patients. Conversion to thoracotomy was necessary in 22 patients $(23 \%)$. Musclesparing thoracotomy was the procedure of choice in 19 patients. Length of stay and major postoperative complications were similar between the thoracoscopy group and the open group. A significantly higher percentage of patients 
was able to receive adjuvant therapy in the thoracoscopy group compared with the open group $(37.2 \%$ for thoracoscopy vs $5.3 \%$ for open, $P=.006$ ). The thoracoscopic and open groups did not differ significantly in overall survival or disease-free survival. The authors concluded that thoracoscopic lobectomy for advanced lung cancer can be performed safely with an acceptable mortality rate, although with a higher conversion rate than thoracoscopic lobectomy for early-stage NSCLC.

Kim and colleagues [9] analyzed the outcomes of unexpected pathologic N1 and N2 disease after thoracoscopic lobectomy for clinical stage I NSCLC. The medical records of 89 patients were reviewed retrospectively to assess clinical characteristics, early postoperative complications, recurrence patterns, and survival. Complications occurred in 16 patients $(18 \%)$. For patients with N1 disease, overall survival was $98 \%$ at 1 year and $98 \%$ at 3 years. For patients with $\mathrm{N} 2$ disease, overall survival was $98 \%$ at 1 year and $89 \%$ at 3 years. The authors concluded that survival after thoracoscopic lobectomy for patients with pathologic N1 or N2 disease was comparable with survival after lobectomy through a thoracotomy. However, clinicians must continue to collect and evaluate long-term follow-up data in larger numbers of patients to ensure that a thoracoscopic approach does not compromise oncologic efficacy.

The conversion rate to thoracotomy in the current study was $4 \%$, which is relatively low in comparison with other series. ${ }^{1,7-9,14}$ The conversion rate was not higher for tumors $>3 \mathrm{~cm}$ or for central tumors. Similarly, Hennon and associates ${ }^{8}$ did not find an association between larger tumors and need for conversion. The conversion rate was increased for patients with clinically node-positive disease, which is likely as result of the fact that involvement of hilar nodes can increase the difficulty of dissection around the pulmonary hilar structures. In this study, conversion to thoracotomy did not increase mortality but did result in increased morbidity, primarily because of an increased rate or postoperative transfusion. When planning a thoracoscopic approach in the setting of clinically positive nodes, surgeons should consider discussing with the patient preoperatively the potentially higher chance of conversion. In addition, surgeons may also wish to have a lower threshold to conversion in this setting, especially when they are early in their thoracoscopic lobectomy experience.

As the experience with thoracoscopic lobectomy has grown, thoracoscopy is now used for potentially challenging technical situations such as previous thoracic surgery and following induction therapy. In addition, the thoracoscopic approach is currently applied to more complex resections, including chest wall resection, sleeve lobectomy, and pneumonectomy. ${ }^{10-12}$ It appears that in experienced centers, these procedures are performed with acceptable morbidity and mortality. As the application of thoracoscopy expands to more complex situations, it is important to determine risk factors for potential complications to maximize patient safety. A major strength of this study is that it includes a large number of patients, allowing the creation of a model for morbidity that incorporates multiple clinical variables to elucidate those factors.

The main limitation of this study is the retrospective nature and the selection bias in which patients were chosen for a thoracoscopic approach, particularly early in experience. However, approximately $20 \%$ of patients who underwent a thoracoscopic approach in recent years have had clinically positive nodes. This shift in distribution reflects a general institutional practice of performing thoracoscopic exploration in most patients, even when a thoracotomy is considered likely based on expected difficulty with hilar exposure and dissection as a result of tumor size or location. Thoracoscopic exploration may identify unexpected metastatic disease or another indicator of "unresectability" and may spare the patient a thoracotomy, which likely will allow the patient to begin other needed systemic therapy more quickly.

The positive effects of approach on outcome in this study also cannot necessarily be generalized immediately to all thoracic surgeons, considering the extensive experience of surgeons at our institution with thoracoscopic lobectomy. In particular, the majority of tumors in this study were $<3$ $\mathrm{cm}$, and only $9 \%(\mathrm{n}=83)$ were $>5 \mathrm{~cm}$. Surgeons may not want to attempt a thoracoscopic approach for tumors $>3 \mathrm{~cm}$ until they feel completely comfortable with a thoracoscopic approach for smaller tumors. The decision of if and when to convert to thoracotomy should also be based on the surgeon's overall experience with a thoracoscopic approach, and less-experienced thoracoscopic surgeons should likely have a lower threshold for conversion when dissection is difficult. However, surgeons who become comfortable with thoracoscopic lobectomy can likely achieve similar results to those shown in this series and should consider this approach preferentially for lung cancer in all patients, even for larger tumors and in the presence of adhesions from previous surgery or higher cancer stages.

\section{References}

1. Whitson BA, Groth SS, Duval SJ, Swanson SJ, Maddaus MA. Surgery for earlystage non-small cell lung cancer: a systematic review of the video-assisted thoracoscopic surgery versus thoracotomy approaches to lobectomy. Ann Thorac Surg. 2008;86:2008-16.

2. Villamizar NR, Darrabie MD, Burfeind WR, Petersen RP, Onaitis MW, Toloza E, et al. Thoracoscopic lobectomy is associated with lower morbidity compared with thoracotomy. J Thorac Cardiovasc Surg. 2009;138:419-25.

3. Paul S, Altorki NK, Sheng S, Lee PC, Harpole DH, Onaitis MW, et al. Thoracoscopic lobectomy is associated with lower morbidity than open lobectomy: a propensity-matched analysis from the STS database. J Thorac Cardiovasc Surg 2010;139:366-78.

4. Berry MF, Hanna J, Tong BC, Burfeind WR Jr, Harpole DH, D'Amico TA, et al. Risk factors for morbidity after lobectomy for lung cancer in elderly patients. Ann Thorac Surg. 2009;88:1093-9.

5. Cattaneo SM, Park BJ, Wilton AS, Seshan VE, Bains MS, Downey RJ, et al. Use of video-assisted thoracic surgery for lobectomy in the elderly results in fewer complications. Ann Thorac Surg. 2008;85:231-5.

\section{The Journal of Thoracic and Cardiovascular Surgery • Volume 145, Number 2}


6. Hartwig MG, D'Amico TA. Thoracoscopic lobectomy: the gold standard for early-stage lung cancer? Ann Thorac Surg. 2010;89:S2098-101.

7. Swanson SJ, Herndon JE II, D'Amico TA, Demmy TL, McKenna RJ Jr, Green MR, et al. Video-assisted thoracic surgery lobectomy: report of CALGB 39802: a prospective, multi-institution feasibility study. J Clin Oncol. 2007;25:4993-7.

8. Hennon M, Sahai RK, Yendamuri S, Tan W, Demmy TL, Nwogu C. Safety of thoracoscopic lobectomy in locally advanced lung cancer. Ann Surg Oncol. 2011;18:3732-6.

9. Kim HK, Choi YS, Kim J, Shim YM, Kim K. Outcomes of unexpected pathologic $\mathrm{N} 1$ and N2 disease after video-assisted thoracic surgery lobectomy for clinical stage I non-small cell lung cancer. J Thorac Cardiovasc Surg. 2010;140:1288-93.

10. Berry MF, Onaitis MW, Tong BC, Balderson SS, Harpole DH, D'Amico TA. Feasibility of hybrid thoracoscopic lobectomy and en-bloc chest wall resection. Eur J Cardiothorac Surg. 2012;41:888-92.

11. Mahtabifard A, Fuller CB, McKenna RJ Jr. Video-assisted thoracic surgery sleeve lobectomy: a case series. Ann Thorac Surg. 2008;85:S729-32.

12. Nwogu CE, Yendamuri S, Demmy TL. Does thoracoscopic pneumonectomy for lung cancer affect survival? Ann Thorac Surg. 2010;89:S2102-6.

13. Society of Thoracic Surgeons. STS general thoracic surgery database version 2.08 training manual. Available from: http://www.sts.org/sites/default/files/ documents/pdf/trainingmanuals/adult2.61/Section_P_COMPLICATIONS.pdf.

14. Onaitis MW, Petersen PR, Balderson SS, Toloza E, Burfeind WR, Harpole DH Jr, et al. Thoracoscopic lobectomy is a safe and versatile procedure: experience with 500 consecutive patients. Ann Surg. 2006;244:420-5.

15. Demmy TL, Curtis JJ. Minimally invasive lobectomy directed toward frail and high-risk patients: a case control study. Ann Thorac Surg. 1999;68:194-200.

16. Nagahiro I, Andou A, Aoe M, Sano Y, Date H, Shimizu N. Pulmonary function, postoperative pain, and serum cytokine level after lobectomy: a comparison of VATS and conventional procedure. Ann Thorac Surg. 2001;72:362-5.

17. Tschernko E, Hofer S, Beiglmayer C, Wisser W, Haider W. Video-assisted wedge resection/lobectomy versus conventional axillary thoracotomy. Chest. 1996;109: $1636-42$.

18. Kaseda S, Aoki T, Hangai N, Shimizu K. Better pulmonary function and prognosis with video-assisted thoracic surgery than with thoracotomy. Ann Thorac Surg. 2000;70:1644-6.

19. McKenna RJ, Houck W, Fuller CB. Video-assisted thoracic surgery lobectomy: experience with 1,100 cases. Ann Thorac Surg. 2006;81:421-6.

20. Nomori H, Horio H, Naruke T, Suemasu K. What is the advantage of a thoracoscopic lobectomy over a limited anterior thoracotomy procedure for lung cancer surgery? Ann Thorac Surg. 2001;72:879-84.

21. Burfeind WR Jr, Jaik NP, Villamizar N, Toloza EM, Harpole DH Jr, D'Amico TA. A cost-minimisation analysis of lobectomy: thoracoscopic versus posterolateral thoracotomy. Eur J Cardiothorac Surg. 2010;37:827-32.

22. Ceppa DP, Kosinski AS, Berry MF, Tong BC, Harpole DH, Mitchell JD, et al. Thoracoscopic lobectomy has increasing benefit in patients with poor pulmonary function: a Society of Thoracic Surgeons database analysis. Ann Surg. 2012;256: 487-93.

23. Onaitis M, D'Amico TA. Lung cancer: minimally invasive approaches. In: Selke FW, de Nido PJ, Swanson SJ, eds. Sabiston \& Spencer surgery of the chest. vol. 1, 7th ed. Philadelphia: Elsevier Saunders; 2005:277-84.

24. Petersen RP, Pham D, Burfeind WR, Hanish SI, Toloza EM, Harpole DH Jr, et al. Thoracoscopic lobectomy facilitates the delivery of chemotherapy after resection for lung cancer. Ann Thorac Surg. 2007;83:1245-9.

25. Nicastri DG, Wisnivesky JP, Litle VR, Yun J, Chin C, Dembitzer FR, et al. Thoracoscopic lobectomy: report on safety, discharge independence, pain, and chemotherapy tolerance. J Thorac Cardiovasc Surg. 2008;135:642-7.

\section{Discussion}

Dr Joseph Shrager (Stanford, Calif). I appreciate the opportunity to discuss. Mark, very nice paper from what is obviously one of the most experienced video-assisted thorascopic surgery (VATS) lobectomy centers and I will not resist the opportunity to remind you that I am probably - I think I am the first person who ever took you through a lobectomy when you were a PGY4 at Penn. Is that right?

Dr Berry. That is right. At Pennsylvania Hospital.
Dr Shrager. So I take pride there.

Moderator. Watch out. That means he's about to get you. [laughter]

Dr Shrager. I think it is only natural as you gain more experience with a newer procedure like VATS lobectomy that unless you feel there is a compelling reason not to take on tougher tumors that is what you are going to do. I think you have shown very nicely with these data that, in your hands at least, in the hands of the most experienced place in the country, moving to these more challenging tumors does not increase morbidity and mortality in any major way anyway, so it is doable if you are very experienced. The more important question I think is not answered here and that is: Is there an oncologic reason not to tackle these tumors? In other words, should we be doing this? I think every survival analysis that is really scientifically done, published for VATS lobectomy, is focused on stage I tumors, so we do not have any data yet about survival for stage II and stage III tumors that are done thoracoscopically and that is what we would need to see to really answer that second question. My personal bias is that when we do VATS lobectomies we tend to fragment lymph nodes, leave little pieces of it stuck to the bronchus-where we would normally get it out if we were open-and just do, generally, a less clean job. That is not a problem in cases that eventually prove to be N0, but I feel very bad when I have done a VATS lobectomy and the case ends up being $\mathrm{N} 1$ or N2. I feel like I have done the patient a disservice because I might have left a little tiny piece of something. My hunch is that when we get larger series we are going to be able to show reduced survival for N1 and N2. So, my first question is: What is your gut feeling about that statement that clearance is not quite as good and that might lead to less survival in the long term?

Dr Berry. Well, I do agree that when you are dissecting the nodes out thoracoscopically you usually fragment them more than when you are doing an open procedure, particularly when you are doing your mediastinal lymph node dissection in level 7 or 4R. My personal feeling is that as long as you are persistent at clearing out everything that you see, you can do just as good of a job. We have not looked at the survival of the patients in the study. We have looked at the survival after thoracoscopic lobectomy and compared it with thoracotomy. We have not published those results, but the preliminary investigation suggests that the outcomes are either the same or maybe better after VATS lobectomy. The reason we really have not tried to publish those yet is we are still trying to make sure that we really do a good job of stratifying the patients and making sure they are matched well because there really should not be that much of a difference in the long term between VATS and a thoracotomy approach.

We have had a few papers published by our radiation oncology colleagues at Duke who have developed models looking at local recurrences as well as distant failures, and one of the variables that they have included is a VATS approach. They have never found that a VATS approach predicts worse outcomes.

Dr Shrager. I suspect that it is so rare that the little fragment of node you leave behind actually is the malignant fragment that it would take a huge study to show it. Maybe it really does not matter.

Second question: Do you have information on exactly what were the causes of conversion to thoracotomy? If they were done to ensure clearance of nodes in cases when you could not 
get the nodes off an important structure, that would be appropriate and expected, but if they were for bleeding, which is suggested, really, by the fact that you have increased transfusions in the patients who were converted, that would be more concerning. Although you did not show any increased deaths in that group, I am worried that in less-experienced hands you might have some patients die from intraoperative hemorrhage.

Dr Berry. I do not know the exact numbers for these patients, but in previous studies that we have done, probably about half the conversions are done for bleeding. It can be hard to recreate the situation retrospectively because most of the time the op note will be pretty bland in saying bleeding was encountered, so we converted to thoracotomy. My personal experience with cases that require conversion as a result of bleeding is that you can control things pretty well and you can convert and take care of problems in a very controlled fashion. Most bleeding is from pulmonary artery branches, which are low pressure and can typically be controlled with gentle pressure. I think about half the cases were for bleeding and probably about half the cases were just could not expose the structures that we wanted to expose or there was something else that required getting in and being able to palpate to determine whether something was resectable.

Dr Shrager. Last quick question. Clinically node-positive patients had double the conversion rate and an increased transfusion rate. You came short of saying we should not do clinically nodepositive patients.

Dr Berry. I think that if somebody has clinically positive nodes you should be prepared both to make sure that the patient is prepared for a thoracotomy and, if they are a marginal candidate, that they would really tolerate that if you think that is going to increase their risk. Despite the increased risk of needing a conversion, most patients who are clinically node positive were still able to get their procedure done with the thoracoscopic approach. I would still say that it is okay to start out thoracoscopically, but just have in mind that there is increased risk that you could run in to trouble, be ready for it, and just make sure that you were prepared for that beforehand. Our anesthesiologists put epidurals in all our patients regardless of whether it is going to be a thoracotomy or a thoracoscopic approach. If you use epidurals selectively, then it might be a good idea that if someone looks like they have PETpositive nodes, have them get an epidural because there is at least a higher chance of getting a thoracotomy.

Dr Ross Bremner (Phoenix, Ariz). Thanks very much. Great paper. When you convert your cases, do you just extend your 4-cm axillary incision and put in a retractor or do you make another posterolateral thoracotomy incision?

Dr Berry. Most of the cases are just extending the utility incision. It depends on at what point in the operation there is a conversion. If it is the type of thing where we put the scope in, start to work around the hilum, and realize that we are not going to be able to do it thoracoscopically, in those patients we usually just make a regular posterolateral thoracotomy incision.

Dr Bremner. So posterolateral thoracotomy would be your preferred approach for a complex operation.

Dr Berry. Yes.

Dr Bremner. I guess my question, then, is: Is there a way that you could advise people who are learning how to do this procedure regarding which cases are going to be really hard? For example, is there a size criteria? As we all know, we see tumors that are 6 or 7 $\mathrm{cm}$ in size that are mediastinal node negative. I mean, is there a cutoff in the size? And what about nodal status? I guess from your paper here you infer that if there are clinically node-positive nodes near the central hilum or near pulmonary arteries, we should probably just start open?

Dr Berry. Based on what we looked at, I do not think I could just pick a criteria that would say these cases are going to require a conversion to thoracotomy. In my experience, and based on the data, I think the tumors that are node positive are the ones that are going, most likely, to require a thoracotomy. We tried to stratify tumor size and see if we could find a size that was going to predict that you could not do it thoracoscopically and we were not able to. There were tumors that were $9 \mathrm{~cm}$ that were able to be resected thoracoscopically in the series.

Dr Bremner. If you are taking a 9-cm tumor out of a 4-cm hole, are you losing the benefit of a VATS lobectomy?

Dr Berry. That is sometimes the hardest part of the case, and it sometimes requires making the incision bigger, but we still are able to do the case without any retraction at all, which we think, ultimately, is probably the reason why people are getting benefit from this.

Dr Bremner. Thanks very much.

Dr Gary Gelfand (Calgary, Alberta, Canada). An excellent paper. I was just curious-Your operative times, I mean in the 2 groups $<3 \mathrm{~cm}$. Did you have any data on operative time? Because at what point does increasing operative time make it not necessarily the optimal economic strategy?

Dr Berry. I cannot really answer that. We do not really have good recordings of operative times in our patient database. Certainly, the more experienced of the surgeons, their operative times are less. Operative time also can depend on the level of resident that is doing the case. In general, we do not use operative time as one of the criteria to decide whether to convert to a thoracotomy. There were a few patients, though, where the op note specifically said "Due to failure to progress in the operation, the procedure was converted to thoracotomy." I can't really give much more detail on the operative time other than that.

Dr Steven R. DeMeester (Los Angeles, Calif). Very nice paper. Just a question. In the patients who have to get converted, do they lose anything? In other words, have you looked at the patients who required conversion and compared them with similar patients who you just started out open? Either in your learning experience, or whatever, was there a downside to trying a VATS approach in terms of blood loss or other complications compared with going straight to an open approach?

Dr Berry. We did not do that. My sense is that the patients who required a conversion because of bleeding probably had a higher transfusion rate than if you had just started straight with thoracotomy. I do not think that the morbidity of the conversion patients, at least in our series, was any different than patients who had a thoracotomy to start with, at least of what we would consider significant complications. Obviously, we would like to avoid transfusions, especially in these people with lung cancer, but the complications that they did have were not life-threatening, and most of the time they did not prolong the patient's hospital stay. My sense is that they ultimately did okay, and no worse than if they just started with a thoracotomy. 